\title{
Post-myocardial infarction ventricular septal defect. Is it better to operate on a fresh infarction or to wait? A case study
}

\author{
Bogdan Suder, Łukasz Janik, Grzegorz Wasilewski, Janusz Konstanty-Kalandyk, Jerzy Sadowski, \\ Bogusław Kapelak, Piotr Ceranowicz, Krzysztof Bartuś
}

Department of Cardiovascular Surgery and Transplantation, Collegium Medicum, Jagiellonian University, Krakow, Poland

Kardiochirurgia i Torakochirurgia Polska 2016; 13 (1): 39-41

\begin{abstract}
The authors present case studies of two patients, aged 76 and 77, who were diagnosed with fresh post-myocardial infarction ventricular septal defects (VSD) and were admitted for urgent surgical intervention. The report is a comment in the discussion concerning the optimal time for surgical intervention.

Key words: ventricular septal defect, VSD, myocardial infarction complications.
\end{abstract}

\section{Introduction}

Post-myocardial infarction ventricular septal defect (post-MI VSD) is an increasingly rare complication of myocardial infarction. Most commonly, it develops within a few days after a transmural $\mathrm{MI}$ involving the septum. Mortality associated with the complication remains high. Conservative treatment is associated with $94 \%$ mortality, while surgical treatment is associated with $47 \%$ mortality during the first 30 days [1]. Despite the improving outcomes, making a decision to perform surgery is complicated by the severe preoperative condition of the patients and the softness of the tissues affected by necrosis. The following two selected case studies are an attempt to participate in the discussion concerning the treatment of this exceptionally difficult complication.

The aim of the study is to present cases of two selected patients who were admitted to cardiac departments with signs of acute ST-segment elevation myocardial infarction (STEMI) complicated by the occurrence of post-MI VSD, followed by a discussion of challenges associated with the therapeutic decisions and the results of surgical treatment.

\section{Material and methods}

Both studied patients suffered from post-MI VSD. The first was a 77-year-old woman whose medical history included many years of arterial hypertension and dyslipi-

\section{Streszczenie}

W pracy przedstawiono wybrane przypadki pacjentów, 76-letniego i 77-letniego, z rozpoznanym świeżym pęknięciem przegrody międzykomorowej (ventricular septal defects - VSD), zakwalifikowanych do pilnego zabiegu chirurgicznego, jako głos w dyskusji nad optymalnym czasem chirurgicznej interwencji. Słowa kluczowe: ubytek przegrody międzykomorowej, VSD, powikłania zawału serca.

demia; she sustained an acute myocardial infarction with ST-segment elevation (STEMI).

The second patient was a 76-year-old man after aortic valve replacement ( 23 years prior), receiving long-term coagulation, overweight and suffering from persistent atrial fibrillation, arterial hypertension, and hypercholesterolemia; he had previously undergone colectomy and chemotherapy due to colon cancer. Both patients were qualified for surgical treatment by the heart team.

\section{Results}

\section{Patient 1}

A 77-year-old female patient underwent coronary angiography which revealed: a subtotal short-segment stenosis in the medial segment of the anterior interventricular branch of the left coronary artery (LAD, left anterior descending) with peripheral inflow impairment (TIMI-2), a critical stenosis of the proximal part of the left circumflex artery (LCX), as well as a chronic total occlusion (CTO) of the right coronary artery with blood flowing into the posterior descending artery (PDA) via collateral circulation from the left coronary artery. Concurrent angioplasty and bare-metal stent implantation was performed. On the next day, the patient was in moderate general condition and hemodynamically stable (ABP 100/70 mmHg, HR 80 bpm); a fresh murmur was observed above the heart during physi- 
cal examination. Transthoracic echocardiography revealed moderately reduced left ventricular ejection fraction (LVEF approx. $40 \%$ ) with akinesia of the apex and the middle segments of the anterior left ventricular wall and interventricular septum. In the apical segment of the interventricular septum, a post-MI defect (aVSD) was visualized: $3.8 \mathrm{~mm}$ in diameter, clear left-to-right shunt, no fluid in the pericardial sac. Echocardiographic examinations performed on subsequent days demonstrated a gradual reduction of LVEF, a growing amount of fluid in the pericardial cavity, and the formation of an aneurysm on the anterior left ventricular wall. After a cardiac surgery consultation, the patient was qualified for urgent VSD repair and, on the $7^{\text {th }}$ day after the infarction, was transferred to the Clinic of Cardiovascular Surgery and Transplantology of the Jagiellonian University Medical College (JUMC). On the $8^{\text {th }}$ day after the myocardial infarction, alloplasty of the aVSD was performed: a GoreTex patch $(2 \times 3$ in size) was implanted from the side of the left ventricle (access was obtained through an incision in the infarcted area of the anterior left ventricular wall); this was followed by aneurysmectomy and ventriculoplasty using Dor's method. Intraoperative examination revealed delicate, fragile tissue in the infarcted zone, offering little support for sutures. Control transesophageal echocardiography performed intraoperatively did not demonstrate any leaks. On the $3^{\text {rd }}$ postoperative day, another echocardiographic examination was performed in the Intensive Care Unit, revealing VSD recurrence. In view of the patient's stable condition, she was scheduled for planned reoperation. On the $10^{\text {th }}$ postoperative day, the defect of the interventricular septum (approximately $4 \mathrm{~mm}$ in diameter) persisted in the apical segment with a bidirectional shunt; left ventricular ejection fraction approx. $25 \%$. On the $12^{\text {th }}$ day, the hemodynamically stabilized patient was discharged from the Clinic.

\section{Patient 2}

A 76-year-old male patient with numerous burdensome factors was admitted to the Clinic of Metabolic Diseases (JUMC) in order to undergo diagnostics regarding significant body mass loss. When interviewed, the patient reported hemoptysis, resting dyspnea, and chest pain which had persisted for several weeks. Approximately 10 days before hospitalization, the patient experienced strong, burning chest pain. Out-patient imaging diagnostics revealed degenerative changes in the vertebral column, which were considered to be the cause of the pain. However, electrocardiography demonstrated signs of infarction of the anterior wall of the heart, which had not been present on the electrocardiogram obtained approx. 1 month earlier. Laboratory investigation revealed elevated inflammatory markers; myocardial necrosis markers were within normal limits. Echocardiography visualized an aneurysm of the left ventricular apex with signs of fibrosis; LVEF approx. $50 \%$. Chest X-ray demonstrated stasis above the lung fields and signs of bronchopneumonia in the right lung. After a cardiac consultation, the patient was scheduled for expedited coronary angiography. During the subsequent days of hospitalization, the patient's general condition deteriorated: he manifested hypotonia, renal failure, and reduced diuresis. Diuretic treatment was introduced, and an intravenous infusion of dopamine was started. On the $10^{\text {th }}$ day of hospitalization, due to signs of the approaching cardiogenic shock, the patient was urgently transferred to the $2^{\text {nd }}$ Clinic of Cardiology (JUMC), where another echocardiographic examination was performed, visualizing an antero-apical VSD (approx. $15 \mathrm{~mm}$ in diameter) with a left-to-right shunt and a developed aneurysm of the left ventricular apex; LVEF approx. $45 \%$. Coronarography demonstrated an occlusion of the medial segment of the anterior interventricular branch and a $70 \%$ stenosis of the proximal segment of the RCA. In order to stabilize the patient, dopamine administration was increased, continuous infusions of noradrenaline and furosemide were introduced, and an intra-aortic balloon pump (IABP) was implanted. On the $4^{\text {th }}$ day of his stay on the cardiac ward, the patient was transferred to the Clinic of Cardiovascular Surgery and Transplantology (JUMC) due to his deteriorating condition. Immediately, alloplasty of the VSD was performed with a Gore-Tex patch, followed by aneurysmectomy and ventriculoplasty using Dor's method; the left internal thoracic artery was anastomosed with the anterior interventricular branch of the left coronary artery. Intraoperatively, well-organized and fibrosed post-MI scar tissue was revealed. Control echocardiography demonstrated no interventricular shunt; LVEF was approx. 20\%. Over the following days, the dosage of pressor amines was reduced; on the $8^{\text {th }}$ postoperative day, the IABP was removed; from the $9^{\text {th }}$ postoperative day, the patient was conscious and breathing on his own, periodically receiving CPAP support. Control echocardiographic examinations demonstrated a gradual increase of LVEF to approx. 35\%. No interventricular shunt was visualized. The patient's prolonged stay at the Intensive Care Unit was caused by concomitant pneumonia.

\section{Discussion}

In the era of transcutaneous coronary interventions, post-MI rupture of the interventricular septum has become a rare complication of acute myocardial infarction; notwithstanding, it is still associated with high mortality reaching $94 \%$ in patients treated conservatively and $47 \%$ in patients undergoing cardiac surgery procedures (30-day mortality) [1]. In its natural course, the associated initial symptoms are typically mild and may sometimes be limited to the appearance of a new holosystolic murmur; in spite of this, the condition quickly progresses to severe heart failure, pulmonary edema, and cardiogenic shock due to left ventricular overload, increased pulmonary flow, and increased venous return to the left ventricle.

Closing the shunt and stabilizing the hemodynamic condition of the patient is of paramount importance for the prognosis, but the optimal time of intervention remains debatable [2].

Without surgical intervention, the first day after postMI VSD is survived by approx. $75 \%$ of patients, the first 
week - approx. $50 \%$, two weeks - 30\%; only $4-15 \%$ of patients survive the first month $[1,3]$. These data and the dynamics of hemodynamic deterioration form arguments for expediting surgical intervention. However, during the acute phase of the infarction, the necrotic tissue is very fragile and does not offer solid support for patches and sutures. This was the case with the first presented patient who underwent surgery on the $8^{\text {th }}$ day after the infarction. Proceeding quickly normalizes the patient's critical condition, but is associated with high frequency of VSD recurrence, which constitutes an unfavorable prognostic factor and is associated with increased postoperative mortality rates and need for reintervention $[2,5]$.

The more time passes between the myocardial infarction and the procedure, the better the outcomes of surgical treatment for ventricular septal rupture are. Delaying the surgical procedure offers time for the necrosis to organize and for the scar to undergo fibrosis, which significantly improves the mechanical resistance of the tissues in the infarct zone. Such organized necrosis was observed in the second discussed patient. In this case, the surgery was performed approx. 25 days from the myocardial infarction. Therefore, it appears desirable to strive for hemodynamic stabilization of the patient and delay the planned procedure in order to improve treatment conditions [2-4, 6].

The efficacy of pharmacological methods in stabilizing aVSD patients is low $[1,5]$, but the influence of pharmacological treatment, especially with catecholamines, cannot be discarded completely. Notwithstanding, due to its limited impact, attempts to delay the procedure are made using equipment for mechanical circulatory support. Gregoric et al. [6] described the case of a 58-year-old male patient with an infarction of the inferior myocardial wall and a post-MI ventricular septal rupture in the postero-basal segment. In order to stabilize the patient's hemodynamic condition, a TandemHeart centrifugal pump was implanted as a left ventricular assist device (LVAD) using a minimally invasive procedure. After 10 days of support, the shunt was closed surgically, which was followed by further 8 days of support in order to allow the left ventricle to gradually regain its function after the procedure. Intraoperatively, the tissues of the infarct zone were well organized and offered sufficient support for sutures. No shunt was visualized during the postoperative course. A similar case was described by Patenè et al. [3]: their patient was a 45-year-old male with inferior myocardial infarction and post-MI VSD in the postero-basal segment, which occurred on the $10^{\text {th }}$ day after the infarction and quickly led to cardiogenic shock. In order to stabilize the patient's hemodynamic condition, an Impella Recover axial micropump was implanted as an LVAD using a minimally invasive procedure. After 2 weeks of support, coronary artery bypass grafting was performed, and the defect was closed; the post-MI scar was organized, and there was no leak recurrence after the surgery. In both cases, echocardiographic examinations demonstrated significant leak reduction during the time the support was provided; not only did it result in improved cardiac output, but it also unburdened the right ventricle and prevented its insufficiency. Many similar reports are available. Therefore, it appears that minimally invasive systems for mechanical circulatory support are also promising in terms of facilitating the choice of the appropriate moment for performing surgery in patients with post-MI VSD.

If the patient remains unstable, and their general condition deteriorates, life-saving surgery should be attempted immediately.

Unfortunately, although a relatively substantial number of relevant case studies are available, results from studies on large groups of patients with post-MI VSD remain lacking. Notwithstanding, most reports, including the present study, corroborate the thesis that the only method of improving the results of treatment provided to patients with this challenging complication is to attempt hemodynamic stabilization and delay the surgical procedure.

\section{Conclusions}

1. In patients diagnosed with post-MI VSD hemodynamic stabilization should always be attempted.

2. Delaying the procedure appears to be the only method of improving the outcomes of surgical treatment for post-MI VSD.

\section{Disclosure}

Authors report no conflict of interest.

\section{References}

1. Crenshaw BS, Granger CB, Birnbaum Y, Pieper KS, Morris DC, Kleiman NS, Vahanian A, Califf RM, Topol EJ. Risk factors, angiographic patterns, and outcomes in patients with ventricular septal defect complicating acute myocardial infarction. GUSTO-I (Global Utilization of Streptokinase and TPA for Occluded Coronary Arteries) Trial Investigators. Circulation 2000; 101: 27-32.

2. Deja MA, Szostek J, Widenka K, Szafron B, Spyt TJ, Hickey MS, Sosnowski AW. Post infarction ventricular septal defect - can we do better? Eur J Cardiothorac Surg Aug 2000; 18: 194-201.

3. Patanè F, Grassi R, Zucchetti MC, Ceresa F, Amata AD, Zingarelli E, Sansone F, Marte F, Patanè S. The use of Impella Recover in the treatment of post-infarction ventricular septal defect: a new case report. Int J Cardiol 2010; 144: 313-315.

4. Szkutnik M, Bialkowski J, Chodor P, Banaszak P, Polonski L, Nowak J, Zembala M. Transcatheter closure of a residual postmyocardial infarction ventricular septal defect using Amplatzer atrial septal occluder. Folia Cardiol 2001; 8: 685-689.

5. Menon V, Webb JG, Hillis LD, Sleeper LA, Abboud R, Dzavik V, Slater JN, Forman R, Monrad ES, Talley JD, Hochman JS. Outcome and profile of ventricular septal rupture with cardiogenic shock after myocardial infarction: a report from the SHOCK Trial Registry. SHould we emergently revascularize Occluded Coronaries in cardiogenic shock? J Am Coll Cardiol 2000; 36 (3 Suppl A): 1110-1116.

6. Gregoric ID, Bieniarz MC, Arora H, Frazier OH, Kar B, Loyalka P. Percutaneous ventricular assist device support in a patient with a postinfarction ventricular septal defect. Tex Heart Inst J 2008; 35: 46-49. 